\title{
Metabolic syndrome, plasma lipid, lipoprotein and glucose levels, and endometrial cancer risk in the European Prospective Investigation into Cancer and Nutrition (EPIC)
}

\begin{abstract}
Anne E Cust ${ }^{1,2,3}$, Rudolf Kaaks ${ }^{1,4}$, Christine Friedenreich ${ }^{1,5}$, Fabrice Bonnet ${ }^{3,6}$, Martine Laville ${ }^{3,6}$, Anne Tjønneland ${ }^{7}$, Anja Olsen ${ }^{7}$, Kim Overvad $^{8}{ }_{\text {, Marianne }}$ Uhre Jakobsen ${ }^{8}$, Véronique Chajès ${ }^{9}$, Françoise Clavel-Chapelon ${ }^{g}$, MarieChristine Boutron-Ruault ${ }^{9}$, Jakob Linseisen ${ }^{4}$, Annekatrin Lukanova ${ }^{4}$, Heiner Boeing ${ }^{10}$, Tobias Pischon ${ }^{10}$, Antonia Trichopoulou ${ }^{11}$, Bamia 'Christina ${ }^{11}$, Dimitrios Trichopoulos ${ }^{11,12}$, Domenico Palli ${ }^{13}$, Franco Berrino ${ }^{14}$, Salvatore Panico ${ }^{15}$, Rosario Tumino ${ }^{16}$, Carlotta Sacerdote ${ }^{17}$, Inger Torhild Gram ${ }^{18}$, Eiliv Lund ${ }^{18}$, J $R$ Quirós ${ }^{19}$, Noémie Travier ${ }^{20}$, Carmen MartínezGarcía $^{21}$, Nerea Larrañaga ${ }^{22}$, María-Dolores Chirlaque ${ }^{23}$, Eva Ardanaz ${ }^{24}$, Göran Berglund $^{25}$, Eva Lundin ${ }^{26}$, H Bas Bueno-de-Mesquita ${ }^{27}$, Fränzel J B van Duijnhoven $^{27}$, Petra H M Peeters ${ }^{28}$, Sheila Bingham ${ }^{29,30}$, Kay-Tee Khaw ${ }^{31}$, Naomi Allen ${ }^{32}$, Tim Key ${ }^{32}$, Pietro Ferrari ${ }^{1}$, Sabina Rinaldi ${ }^{1}$, Nadia Slimani ${ }^{1}$ 'and Elio Riboli ${ }^{33}$
\end{abstract}

\footnotetext{
${ }^{1}$ Nutrition and Hormones Unit, International Agency for Research on Cancer, Lyon, France

${ }^{2}$ School of Public Health, University of Sydney, Level 2, K25-Medical Foundation Building, Sydney, New South Wales, Australia

${ }^{3}$ Center for Research in Human Nutrition Rhône-Alpes, Université Lyon 1, Lyon, France

${ }^{4}$ Division of Cancer Epidemiology, German Cancer Research Center (DKFZ), Heidelberg, Germany

${ }^{5}$ Division of Population Health and Information, Alberta Cancer Board, Calgary, Alberta, Canada

${ }^{6}$ UMR INSERM U449/INRA 1235, Lyon, France

${ }^{7}$ Institute of Cancer Epidemiology, Danish Cancer Society, Copenhagen, Denmark

${ }^{8}$ Department of Clinical Epidemiology, Aarhus University Hospital, Aalborg, Denmark

${ }^{9}$ Inserm ERI 20, Institut Gustave Roussy, Paris-Sud University, EA4045 Villejuif, France

${ }^{10}$ German Institute of Human Nutrition Potsdam-Rehbruecke, Nuthetal, Germany

${ }^{11}$ Department of Hygiene and Epidemiology, University of Athens Medical School, Athens, Greece

${ }^{12}$ Hellenic Health Foundation, Athens, Greece

${ }^{13}$ Molecular and Nutritional Epidemiology Unit, CSPO-Scientific Institute of Tuscany, Florence, Italy

${ }^{14}$ Nutritional Epidemiology Unit, National Cancer Institute, Milan, Italy

${ }^{15}$ Department of Clinical and Experimental Medicine, Federico II University, Naples, Italy

${ }^{16}$ Cancer Registry, Azienda Ospedaliera 'Civile M P Arezzo', Ragusa, Italy

${ }^{17}$ CPO-Piemonte, Torino, Italy

${ }^{18}$ Faculty of Medicine, Institute of Community Medicine, University of Tromsø, Tromsø, Norway

${ }^{19}$ Public Health and Health Planning Directorate, Asturias, Spain

${ }^{20}$ Department of Epidemiology and Cancer Registry, Catalan Institute of Oncology, Barcelona, Spain

${ }^{21}$ Andalusian School of Public Health, Granada, Spain

${ }^{22}$ Public Health Department of Gipuzkoa, Basque Government, San Sebastian, Spain

${ }^{23}$ Epidemiology Department, Murcia Health Council, Murcia, Spain

${ }^{24}$ Public Health Institute of Navarra, Pamplona, Spain

${ }^{25}$ Department of Medicine, Malmö University Hospital, Lund University, Malmö, Sweden

${ }^{26}$ Department of Medical Biosciences, Umeå University, Umeå, Sweden

${ }^{27}$ National Institute of Public Health and the Environment, Centre for Nutrition and Health, Bilthoven, The Netherlands

${ }^{28}$ Julius Center for Health Sciences and Primary Care, University Medical Center, Utrecht, The Netherlands

${ }^{29}$ MRC Dunn Human Nutrition Unit, Cambridge, UK

${ }^{30}$ Department of Public Health and Primary Care, MRC Centre for Nutritional Epidemiology in Cancer Prevention and Survival, University of Cambridge, Cambridge, UK

${ }^{31}$ Clinical Gerontology, Department of Public Health and Primary Care, University of Cambridge, Cambridge, UK

${ }^{32}$ Cancer Research UK Epidemiology Unit, University of Oxford, Oxford, UK

${ }^{33}$ Department of Epidemiology and Public Health, Imperial College London, London, UK

(Correspondence should be addressed to A E Cust; Email: annec@health.usyd.edu.au)
} 


\section{Abstract}

To clarify the role of metabolic factors in endometrial carcinogenesis, we conducted a case-control study nested within the European Prospective Investigation into Cancer and Nutrition (EPIC), and examined the relation between prediagnostic plasma lipids, lipoproteins, and glucose, the metabolic syndrome (MetS; a cluster of metabolic factors) and endometrial cancer risk. Among pre- and postmenopausal women, 284 women developed endometrial cancer during follow-up. Using risk set sampling, 546 matched control subjects were selected. From conditional logistic regression models, high-density lipoprotein cholesterol (HDL-C) levels were inversely associated with risk body mass index (BMI)-adjusted relative risk (RR) for top versus bottom quartile 0.61 (95\% confidence intervals (Cl) 0.38-0.97), $P_{\text {trend }}=0.02$ ). Glucose levels were positively associated with risk (BMI-adjusted RR top versus bottom quartile $\left.1.69(95 \% \mathrm{Cl} 0.99-2.90), P_{\text {trend }}=0.03\right)$, which appeared stronger among postmenopausal women (BMl-adjusted RR top versus bottom tertile 2.61 (95\% Cl 1.46-4.66), $\left.P_{\text {trend }}=0.0006, P_{\text {heterogeneity }}=0.13\right)$ and never-users of exogenous hormones $\left(P_{\text {heterogeneity }}=0.005\right.$ for oral contraceptive (OC) use and 0.05 for hormone replacement therapy-use). The associations of HDL-C and glucose with risk were no longer statistically significant after further adjustment for obesity-related hormones. Plasma total cholesterol, Low-density lipoprotein cholesterol (LDL-C), and triglycerides were not significantly related to overall risk. The presence of MetS was associated with risk (RR $2.12(95 \% \mathrm{Cl} 1.51-2.97)$ ), which increased with the number of MetS factors $\left(P_{\text {trend }}=0.02\right)$. An increasing number of MetS factors other than waist circumference, however, was marginally significantly associated with risk only in women with waist circumference above the median $\left(P_{\text {interaction }}=0.01\right)$. None of the associations differed significantly by fasting status. These findings suggest that metabolic abnormalities and obesity may act synergistically to increase endometrial cancer risk.

Endocrine-Related Cancer (2007) 14 755-767

\section{Introduction}

Endometrial cancer development is strongly linked to lifestyle factors (Kaaks et al. 2002). Excess weight is a major risk factor (Kaaks et al. 2002) that is estimated to cause up to half of all endometrial cancer cases in developed countries (Calle \& Kaaks 2004). The biologic mechanism through which obesity increases risk is primarily by increasing levels of bioavailable estrogens and reducing levels of progesterone, leading to increased mitotic activity of endometrial cells (Key \& Pike 1988, Kaaks et al. 2002).

There is increasing evidence that insulin resistance (Cust et al. 2007b), hyperinsulinemia (Lukanova et al. 2004, Cust et al. 2007a), and diabetes (Weiderpass et al. 2000) are implicated in the etiology of endometrial cancer, but little is known about the possible role of other related metabolic factors such as hypertension, elevated glucose levels, or unfavorable lipid profiles. Some of these factors may interact with obesity, as several studies have found an increased risk of endometrial cancer associated with hypertension (Weiderpass et al. 2000, Furberg \& Thune 2003), diabetes (Shoff \& Newcomb 1998, Salazar-Martinez et al. 2000, Anderson et al. 2001), and glucose levels (Furberg \& Thune 2003), among overweight or obese women only. Few studies of sufficient size (Hiatt \& Fireman 1986, Swanson et al.
1994) have assessed the relation between lipid and lipoprotein levels and endometrial cancer risk. Prospective studies are needed because the presence or diagnosis of a tumor can lead to alterations in lipid metabolism (Law \& Thompson 1991).

Several of these metabolic factors are components of the metabolic syndrome (MetS), which is a cluster of endocrine-metabolic disturbances characterized by insulin resistance, impaired glucose regulation, hypertension, and a lipid profile consisting of raised triglycerides and low high-density lipoprotein cholesterol (HDL-C; Alberti et al. 2006). It is unknown whether a diagnosis of the MetS or its component factors might be a better predictor of endometrial cancer risk over and above the risk associated with obesity. Furthermore, there have not been any prospective studies, so far, examining the association between the MetS and endometrial cancer risk.

Thus, there were two main objectives of this prospective study: 1) to assess the risk of endometrial cancer in relation to baseline plasma levels of total cholesterol, HDL-C, low-density lipoprotein cholesterol (LDL-C), triglycerides, and glucose, and how these associations are confounded by obesity and other obesity-related biologic markers, including adiponectin, C-peptide, insulin-like growth factor binding proteins (IGFBPs)-1 and -2, and endogenous sex steroid 
hormones and 2) to examine the association between MetS and endometrial cancer risk. To assess these associations, we designed a case-control study among 284 incident cases of endometrial cancer in pre-, peri-, and postmenopausal women and 546 matched controls, nested within the European Prospective Investigation into Cancer and Nutrition (EPIC) cohort study.

\section{Materials and methods}

\section{Study population, baseline data collection, and follow-up}

The EPIC study design, population, baseline data collection, and follow-up procedures for cancer incidence and vital status have been described previously in detail (Riboli \& Kaaks 1997, Riboli et al. 2002). Briefly, 366 500 women and 153500 men in ten western European countries joined the study between 1992 and 1998, and of these, about 386000 also provided a blood sample. The present study includes subjects from eight of the ten participating countries: Denmark, France, Germany, Greece, Italy, The Netherlands, Spain, and the UK. Norway was not included in the present study because blood samples were collected only recently, and very few cases of endometrial cancer had been diagnosed when the present study was initiated. Sweden was not included because a separate study within their cohort had already been planned.

Previous papers describe the baseline assessment of usual diet and lifestyle factors (Riboli et al. 2002), physical activity (Haftenberger et al. 2002a), and anthropometric measures (Haftenberger et al. 2002b). At the time of blood donation, women were classified as premenopausal if they reported having had regular $(>9)$ menstrual cycles over the previous 12 months; postmenopausal if they reported not having had any menses over the past 12 months or if they had a bilateral ovariectomy; and perimenopausal/unknown if they reported one to nine cycles over the past 12 months. Women with incomplete, missing, or equivocal questionnaire data for menopausal status were classified as premenopausal if they were less than 42 years of age, perimenopausal/unknown if they were between 42 and 55 years of age, and postmenopausal if they were older than 55 years.

In Denmark, Italy, The Netherlands, the UK, and Spain, incident cancer cases were identified through record linkage with regional cancer registries. In Germany, France, and Greece, follow-up was based on a combination of methods, including health insurance records, cancer and pathology registries, and active follow-up through study subjects and their next of kin.
Data on vital status in most EPIC study centers were collected from mortality registries at the regional or national level, in combination with data collected by active follow-up (Greece). Vital status was known for 98.4\% of all EPIC participants as of April 2004. For each EPIC study center, closure dates of the study period were defined as the date of the last complete follow-up for both cancer incidence and vital status (dates varied between June 1999 and December 2003 between centers). All participants gave written consent for future analyses of their blood samples, and the study was approved by the local ethics committees in the participating countries and the Internal Review Board of the IARC.

\section{Selection of case and control subjects}

Women were excluded from being a case or control for this study if, at the time of blood donation, they had a previous cancer diagnosis (except non-melanoma skin cancer), or had a hysterectomy. Current users of oral contraceptives (OCs) or hormone replacement therapy (HRT) were also excluded, since they are known to modify hormone and lipid levels and lipoprotein composition (Bradley et al. 1978, Wallace et al. 1979), and may also have effects on glucose levels and blood pressure (Elgee 1970, Medina et al. 2004) depending on the dose and potency of the estrogens and progestins used. We further excluded endometrial tumors of known non-epithelial or non-malignant morphology (World Health Organization 2003). A total of 135953 women from the eight participating countries met these eligibility criteria, of whom 300 women were diagnosed with endometrial cancer during the follow-up period. After further exclusion of 16 cases with insufficient blood sample volume, there were 284 cases included in this study, comprising 67 cases in Denmark, 61 in Italy, 41 in Spain, 36 in The Netherlands, 34 in the UK, 19 in Germany, 17 in France, and 9 in Greece. The cancer diagnosis was confirmed by microscopy (92\%), clinical examination (7\%), or self-report, tomography scan, surgery, or autopsy (1\%). Tumor morphology was specified for 142 cases $(50 \%)$, of which 133 cases $(94 \%)$ were classified as type I (mainly endometrioid and some mucinous adenocarcinomas) and 9 cases $(6 \%)$ as type II (serous papillary, clear cell, or squamous adenocarcinomas; Sherman 2000, World Health Organization 2003).

Control subjects were chosen at random among risk sets consisting of all eligible cohort members alive and free of cancer (except non-melanoma skin cancer) at the time of diagnosis of the index case. An incidence density sampling protocol for control selection was used, such that controls were matched to cases on time 
at risk, and controls could include subjects who later became a case, while each control could also be sampled more than once. Matching criteria included: study center, menopausal status (premenopausal, perimenopausal/unknown, and postmenopausal), age at blood collection ( \pm 6 months), time of day of blood collection $( \pm 1 \mathrm{~h})$, time between blood draw and last consumption of foods or drinks ( $<3 \mathrm{~h}(41.8 \%), 3-6 \mathrm{~h}$ $(20.8 \%),>6 \mathrm{~h}(32.1 \%)$, unknown $(5.3 \%)$ ), and for premenopausal women, phase of menstrual cycle (Kaaks et al. 2005). Two matched controls were identified for 262 cases, and only one matched control could be identified for 22 cases (total of 546 controls).

\section{Blood collection and storage}

A $30 \mathrm{ml}$ blood sample was collected according to a standardized protocol. Filled syringes were kept at $5-10{ }^{\circ} \mathrm{C}$, protected from light, and transferred to a local laboratory for further processing and aliquoting, with the exception of subjects recruited through the Oxford center, where blood samples were transported to a laboratory in Norfolk by mail at ambient temperature. Plasma lipids, lipoproteins, and endogenous hormones have been shown to be fairly stable after storage or transport at ambient temperatures for up to $72 \mathrm{~h}$ (Hankinson et al. 1989, Boyanton \& Blick 2002), however, in whole blood, glucose concentrations can degrade rapidly at room temperature within $24 \mathrm{~h}$ (Boyanton \& Blick 2002). Therefore, we excluded glucose values from all 35 women recruited at the Oxford center. Blood fractions (serum, plasma, red cells, and buffy coat for DNA extraction) were aliquoted into straws, heat-sealed, and stored in liquid nitrogen tanks at $-196{ }^{\circ} \mathrm{C}$, except in Denmark where samples were stored in $1 \mathrm{ml}$ tubes in nitrogen vapor at $-150^{\circ} \mathrm{C}$.

\section{Hormone assays}

Lipid, lipoprotein, and glucose assays were performed at Hôpital Edouard Herriot, Lyon, France, and the other hormone assays were performed at the IARC by laboratory staff blinded to the case-control status of the study subjects. The plasma samples of each matched case-control set were analyzed with sets from the same center, within the same batch on the same day. Cholesterol, HDL-C, and glucose were measured using enzymatic (hexokinase) colorimetric tests, and triglycerides were measured using an enzymatic (GPO-PAP) colorimetric test (Roche Diagnostics). LDL-C was estimated using the Friedewald equation (Friedewald et al. 1972). The intra- and inter-batch coefficients of variation $(\mathrm{CV})$ were 0.8 and $2.1 \%$ for total cholesterol, 1.2 and $2.4 \%$ for triglycerides, 1.2 and $1.7 \%$ for HDL-C, and 0.8 and $2.1 \%$ for glucose. Plasma adiponectin and serum C-peptide, IGFBPs-1 and -2, and endogenous sex steroid hormones (testosterone, estrone, sex hormonebinding globulin (SHBG), free testosterone and, in postmenopausal women, total and free estradiol) have previously been analyzed and reported (Cust et al. $2007 a, b)$.

\section{Presence of the MetS}

The presence of the MetS at baseline was determined for all women (both fasting and non-fasting combined) using two definitions: 1) the National Cholesterol Education Program (NCEP) - Adult Treatment Panel III (Grundy et al. 2005) and 2) the International Diabetes Federation (IDF) definition (Alberti et al. 2006). For the NCEP MetS definition, the presence of three or more of the following five components was required: waist circumference $\geq 88 \mathrm{~cm}$, triglycerides $\geq 1.7 \mathrm{mmol} / 1$, HDL-C $<1.29 \mathrm{mmol} / 1$, systolic blood pressure $\geq 130 \mathrm{mmHg}$ or diastolic blood pressure $\geq 85 \mathrm{mmHg}$, and glucose $\geq 5.6 \mathrm{mmol} / \mathrm{l}$. The diagnosis of MetS according to the IDF definition required a waist circumference $\geq 80 \mathrm{~cm}$, plus the presence of two or more other components: elevated triglycerides, low HDL-C, raised blood pressure, or impaired glucose metabolism, using the same cut-points as the NCEP.

A total of 280 cases and 535 matched controls were included in the MetS analyses. A combination of measured and self-reported data was used for the blood pressure and glucose criteria. There were 518 (64\%) women with both measured blood pressure and selfreported hypertension data; $182(22 \%)$ had measured blood pressure only and 115 (14\%) women had selfreported data only. Of the 700 women ( $87 \%$ of controls and $84 \%$ of cases) with measured systolic and diastolic blood pressure, the mean of two measurements was available for $435(62 \%)$ subjects. For the glucose criteria, $776(95 \%)$ women had both plasma glucose values and self-reported diabetes data, $12(1 \%)$ had measured plasma glucose only and 27 women (3\%; mostly Oxford subcohort) had self-reported data only. Individuals receiving pharmacologic treatment for hypertension, hypertriglyceridemia or low HDL-C, or subjects diagnosed with type 2 diabetes, are considered as meeting the respective criteria. However, apart from self-reported hypertension and diabetes, data on pharmacologic treatments were not available for this analysis.

\section{Statistical analyses}

Circulating lipid, lipoprotein, glucose, and hormone levels were $\log$ transformed to normalize their distributions. Pearson's partial correlation coefficients, 
adjusted for age at blood collection, laboratory batch, and case-control status, were estimated to assess correlations.

Conditional logistic regression models were used to estimate relative risks (RRs) and 95\% confidence intervals (CIs) for the associations between exposure variables and endometrial cancer risk. The prospective design and use of incidence density sampling for selecting controls in this study permitted the direct estimation of the RR rather than the odds ratio (Richardson 2004). Quartile cut-points (or tertile cutpoints for subgroup analyses) were based on the distribution of the variable in control subjects in the full study group; these same cut-points were also used for the subgroup analyses. Fasting and non-fasting women had similar geometric mean baseline levels of total cholesterol, HDL-C, LDL-C, and glucose, but triglyceride levels differed significantly by fasting status, after accounting for case-control status, age, laboratory batch, and body mass index (BMI) in an analysis of covariance (data not shown). Thus, for triglycerides, different cut-points were used according to fasting status. Likelihood ratio tests using medians for each quantile category were used to assess linear trends in RRs.

Multivariate models for the analyses of lipids, lipoproteins, and glucose were adjusted for BMI in addition to matching variables. Results were similar when models were adjusted for waist circumference instead of BMI. The average plasma sample storage time was identical for cases and controls (10.4 years), and additional adjustment for storage time did not affect the results. We also examined other potential confounders including age at menarche, age at menopause, parity, age at birth of last child, previous OC use, previous HRT use, smoking status, physical activity level, alcohol intake, average daily glycemic load and glycemic index, and education level. However, the inclusion of these other potential confounders in the regression models did not appreciably change the risk estimates and thus were not included in the regression models. In addition, we examined the effect of adjusting for circulating levels of endogenous sex steroid hormones and other obesityrelated hormones (quartiles, missing). For the MetS multivariate models, we adjusted for waist circumference or mutually adjusted for the individual component MetS factors.

We also examined the possibility of effect modification by menopausal status, fasting status $(\leq 6 \mathrm{~h},>6 \mathrm{~h}$ since last food or drink), BMI (median cut-point: $<26.2$, $\geq 26.2 \mathrm{~kg} / \mathrm{m}^{2}$ ), physical activity level (metabolic equivalent (MET)-h/week, median cut-point), use of OCs or HRT (previous use, never-use), time to diagnosis ( $<2$ years, $\geq 2$ years), and country. $\chi^{2}$ tests, calculating the deviations of logistic $\beta$-coefficients observed in each of the subgroups relative to the overall $\beta$-coefficient, were used to examine heterogeneity of BMI-adjusted risk estimates associated with a doubling ( $\log 2)$ of lipid, lipoprotein, or glucose levels. For the MetS analyses, interactions were examined by adding appropriate interaction terms to the models. All analyses were performed using SAS Statistical Software (version 9.1, SAS Institute, Cary, NC, USA), and statistical significance was inferred at two-sided $P<0.05$.

\section{Results}

Baseline characteristics according to case-control status are described in Table 1. The mean age of women at baseline was 56.9 years. Compared with control subjects, women who developed endometrial cancer during follow-up were more likely to be obese, nulliparous, report having hypertension, have a later age at menopause or earlier age at menarche, and were less likely to have used OCs in the past.

Pearson's partial correlation coefficients, adjusted for age at blood collection, laboratory batch, and case-control status are shown in Table 2. Plasma HDL-C levels were negatively correlated with triglycerides $(r=-0.54)$, glucose $(r=-0.15)$, LDL-C $(r=-0.15)$, C-peptide $(r=-0.36)$, estrogens, free testosterone, measures of adiposity, and (weakly) with glycemic load. Conversely, HDL-C levels were positively correlated with adiponectin $(r=0.46)$, SHBG $(r=0.34)$, and IGFBP-1 and -2 . Total and LDL cholesterol were not correlated with most other factors (data not shown). Glucose and triglycerides were positively correlated with C-peptide $(r=0.26$ and 0.41 respectively) and adiposity, weakly correlated with androgens and estrogens, and negatively correlated with SHBG, IGFBP-1 and -2. The correlations were generally slightly lower after additional adjustment for BMI or waist circumference (data not shown).

In conditional logistic regression analyses adjusted for matching factors only, increasing triglyceride and glucose levels were associated with increased endometrial cancer risk, HDL-C levels were inversely associated with risk, and total cholesterol and LDL-C levels were not associated with risk (Table 3 ). One of our objectives was to examine how these associations may be confounded by obesity and other obesity-related biologic markers. After adjustment for BMI, the associations remained statistically significant for HDL-C and glucose but not for triglycerides (Table 3). When total cholesterol, HDL-C, LDL-C, triglycerides, and glucose were each mutually adjusted in addition to BMIadjustment, only the glucose association remained 
Table 1 Baseline characteristics for women who developed endometrial cancer during follow-up (cases) and control subjects, in a case-control study nested in the European Prospective Investigation into Cancer and Nutrition (EPIC) cohort

\begin{tabular}{|c|c|c|c|}
\hline Baseline characteristic & Cases $^{a}$ & Controls $^{\mathrm{a}}$ & $P$ for difference ${ }^{b}$ \\
\hline \multicolumn{4}{|c|}{ Number } \\
\hline Total number of women & 284 & 546 & \\
\hline Premenopausal ( $n$; 19\%) & 54 & 105 & \\
\hline Postmenopausal ( $n ; 68 \%)$ & 192 & 370 & \\
\hline Perimenopausal/unknown $(n ; 13 \%)$ & 38 & 71 & \\
\hline \multicolumn{4}{|c|}{ Means (5th-95th percentiles) } \\
\hline Age at blood collection & $56.9(45.4-67.9)$ & $56.9(45.0-68.0)$ & \\
\hline Age at diagnosis & $59.9(47.0-71.0)$ & & \\
\hline $\begin{array}{l}\text { Years between blood collection and } \\
\text { diagnosis }\end{array}$ & $3.0(0.0-6.0)$ & & \\
\hline Age at menarche & $13.0(11.0-15.0)$ & $13.3(11.0-16.0)$ & 0.02 \\
\hline $\begin{array}{l}\text { Age at menopause in postmenopausal } \\
\text { women }\end{array}$ & $51.3(45.0-56.0)$ & $49.7(41.0-55.0)$ & 0.0002 \\
\hline $\begin{array}{l}\text { Household and recreational physical } \\
\text { activity }^{c}\end{array}$ & $97.7(24.5-190.6)$ & $106.3(30.0-197.1)$ & 0.01 \\
\hline Body mass index (BMl; kg/m²) & $28.1(20.9-37.6)$ & $26.5(20.2-34.8)$ & $<0.0001$ \\
\hline Waist circumference $(\mathrm{cm})$ & $86.5(67.2-111.5)$ & $83.0(67.7-104.0)$ & $<0.0001$ \\
\hline Waist-hip ratio & $0.82(0.72-0.93)$ & $0.81(0.70-0.93)$ & 0.03 \\
\hline \multicolumn{4}{|c|}{ Percentages } \\
\hline Obese $\left(\mathrm{BMI} \geq 30 \mathrm{~kg} / \mathrm{m}^{2}\right)$ & 32.4 & 18.0 & $<0.0001$ \\
\hline Nulliparous & 19.8 & 10.0 & 0.0002 \\
\hline Previous oral contraceptive use & 32.3 & 41.9 & 0.01 \\
\hline $\begin{array}{l}\text { Previous hormone replacement } \\
\text { therapy use }^{d}\end{array}$ & 22.0 & 16.0 & 0.10 \\
\hline Self-reported diabetes & 3.6 & 3.8 & 0.89 \\
\hline Self-reported hypertension & 30.9 & 21.4 & 0.008 \\
\hline
\end{tabular}

${ }^{\text {a } M i s s i n g ~ v a l u e s ~ a r e ~ e x c l u d e d ~ f r o m ~ c a l c u l a t i o n s . ~}$

${ }^{\mathrm{b}}$ Calculated using two-sided paired $t$-tests for continuous variables and $\chi^{2}$ tests for categorical variables.

${ }^{\mathrm{c} E s t i m a t e d}$ as MET-h/week.

${ }^{\mathrm{d} A m o n g}$ postmenopausal women.

statistically significant $\left(P_{\text {trend }}=0.008\right.$; data not shown). None of the associations remained statistically significant after further adjustment for sex steroid hormones and other obesity-related hormones (Table 3).

When stratified by baseline menopausal status (Table 4), plasma glucose levels were associated with significantly increased risk among postmenopausal women, but not among perimenopausal/unknown or premenopausal women $\left(P_{\text {heterogeneity }}=0.13\right)$. Stratification by the median BMI showed stronger and statistically significant associations between HDL-C, glucose, and endometrial cancer risk among women above the median, and modest non-significant associations among women below the median, although the tests for heterogeneity were not statistically significant $\left(P_{\text {heterogeneity }}=0.09\right.$ for HDL-C and 0.51 for glucose).

In this cohort, $18 \%$ ( $22 \%$ cases, $16 \%$ controls) of postmenopausal women had previously used HRT and $39 \%$ (32\% cases, $42 \%$ controls) of all women had previously used OCs. In stratified analyses, plasma glucose levels were associated with an increased risk among never-users of OCs or HRT, but there was no association among previous users. The BMI-adjusted RR associated with a doubling of glucose levels was 0.29 (95\% CI 0.06-1.38) for previous OC users, 3.88 (95\% CI $1.54-9.77$ ) for never OC users, $P_{\text {heterogeneity }}=0.005$; and 0.10 (95\% CI 0.00-3.63) for previous HRT users, 3.85 (95\% CI 1.50-9.88) for never HRT users, $P_{\text {heterogeneity }}=0.05$. The associations did not significantly differ by fasting status, physical activity, time to cancer diagnosis, or country. For triglycerides, the BMIadjusted RR for the top versus bottom quartile among fasting subjects was 1.58 (95\% CI 0.69-3.63), $P_{\text {trend }}=0.17$ and among non-fasting subjects was 1.18 (95\% CI 0.70-2.00), $P_{\text {trend }}=0.46$. The RR estimates did not appreciably change when we excluded non-type I cases or cases diagnosed within 2 years after study entry.

The presence of MetS was associated with increased risk of endometrial cancer (Table 5). The association was stronger using the NCEP definition (RR 2.12 (95\% CI 1.51-2.97)) than the IDF definition (RR 1.68 (95\% CI 1.23-2.31)). The NCEP RR was attenuated by about half after adjustment for waist circumference, suggesting that 
Table 2 Pearson's partial correlation coefficients ${ }^{a}$ of baseline plasma HDL-C, triglycerides, and glucose levels, with serum peptide and sex steroid hormone levels and measures of body size, physical activity, and diet

\begin{tabular}{|c|c|c|c|}
\hline & HDL-C & Triglycerides & Glucose \\
\hline Triglycerides & $-0.54^{\dagger}$ & & \\
\hline Glucose & $-0.15^{\dagger}$ & $0.16^{\dagger}$ & \\
\hline Total cholesterol & $0.11^{*}$ & $0.35^{\dagger}$ & 0.04 \\
\hline LDL-C & $-0.15^{\dagger}$ & $0.24^{\dagger}$ & 0.04 \\
\hline Adiponectin & $0.46^{\dagger}$ & $-0.32^{\dagger}$ & $-0.11^{*}$ \\
\hline C-peptide & $-0.36^{\dagger}$ & $0.41^{\dagger}$ & $0.26^{\dagger}$ \\
\hline IGFBP-1 & $0.24^{\dagger}$ & $-0.37^{\dagger}$ & $-0.09^{\star}$ \\
\hline IGFBP-2 & $0.32^{\dagger}$ & $-0.30^{\dagger}$ & $-0.17^{\dagger}$ \\
\hline SHBG & $0.34^{\dagger}$ & $-0.31^{\dagger}$ & $-0.22^{\dagger}$ \\
\hline Testosterone & -0.07 & 0.03 & $0.09^{*}$ \\
\hline Free testosterone & $-0.23^{\dagger}$ & $0.17^{\dagger}$ & $0.13^{*}$ \\
\hline Estrone & $-0.07^{\star}$ & $0.10^{*}$ & 0.07 \\
\hline Total estradiol $^{\mathrm{C}}$ & $-0.16^{*}$ & $0.12^{*}$ & $0.14^{*}$ \\
\hline Free estradiol $^{C}$ & $-0.27^{\dagger}$ & $0.22^{\dagger}$ & $0.21^{\dagger}$ \\
\hline Body mass index & $-0.36^{\dagger}$ & $0.29^{\dagger}$ & $0.21^{\dagger}$ \\
\hline Waist circumference & $-0.37^{\dagger}$ & $0.33^{\dagger}$ & $0.19^{\dagger}$ \\
\hline Waist-hip ratio & $-0.26^{\dagger}$ & $0.30^{\dagger}$ & $0.12^{*}$ \\
\hline Physical activity ${ }^{b}$ & 0.04 & -0.02 & $0.08^{*}$ \\
\hline Glycemic load & $-0.08^{*}$ & 0.01 & $-0.09^{\star}$ \\
\hline Glycemic index & -0.05 & 0.04 & -0.03 \\
\hline
\end{tabular}

${ }^{\star} P<0.05 ;{ }^{\dagger} P<0.0001$ (two-sided tests).

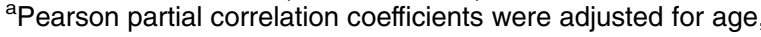
case-control status and laboratory batch.

${ }^{\mathrm{b}} \mathrm{MET}$-h/week of household and recreational physical activity. 'Serum estradiol level was only measured in postmenopausal women because of its considerable intra-individual variation during the menstrual cycle among premenopausal women.

obesity explained much of the increased risk, but the association remained statistically significant. The MetSrisk association was not modified by menopausal status, fasting status, previous exogenous hormone use, or physical activity $\left(P_{\text {interaction }}\right.$ all $\left.>0.10\right)$. The RRs associated with the MetS (NCEP definition) among pre, peri/unknown, postmenopausal were 1.89 (95\% CI 0.75-4.73), 5.90 (95\% CI 1.63-21.35), and 1.92 (95\% CI 1.30-2.82) respectively. The NCEP MetS RR was 2.33 (95\% CI 1.24-4.38) among fasting women and 1.90 (95\% CI 1.25-2.87) among non-fasting women using the same standard cut-points. We additionally examined the MetS RR among non-fasting women only ( $\leq 6 \mathrm{~h}$; $62.8 \%$ of women) using the non-fasting top quartiles of triglycerides $(>1.74 \mathrm{mmol} / \mathrm{l})$ and glucose ( $>4.82 \mathrm{mmol} / \mathrm{l})$, and the non-fasting bottom quartile of HDL-C $(<1.13 \mathrm{mmol} / \mathrm{l})$ as cut-points for those variables while keeping the other cut-points the same; the RR was 2.05 (95\% CI 1.33-3.16).

We also examined the individual component factors that contribute to the MetS (Table 5). Overall, 19\% of subjects had no NCEP MetS factors, and 31, 23, 17, 9, and $1 \%$ of subjects had $1-5$ factors respectively. Waist circumference was strongly associated with endometrial cancer risk, even after adjustment for the other MetS factors. The diagnosis of an increasing number of MetS factors was associated with a significantly increased endometrial cancer risk (crude $P_{\text {trend }}<0.0001$; Table 5). Similar results were found when stratified by fasting status (fasting, $P_{\text {trend }}=0.01$; non-fasting, $P_{\text {trend }}=0.0007$; data not shown). An increasing number of the four nonwaist circumference factors was associated with a marginally significant increasing risk only among women whose waist circumference was above the median $\left(\geq 83 \mathrm{~cm} ; P_{\text {trend }}=0.06\right)$ but not below the median $\left(P_{\text {trend }}=0.69 ; P_{\text {interaction }}=0.01\right.$; Table 5).

The presence of raised blood pressure according to the MetS criteria was not associated with endometrial cancer risk (Table 5). Using quartile cut-points, the RRs for the highest versus lowest quartile for systolic and diastolic blood pressure after adjustment for the other NCEP MetS factors were $1.40(95 \%$ CI $0.81-2.40), P_{\text {trend }}=0.28$ and $1.32(95 \%$ CI $0.77-2.25)$, $P_{\text {trend }}=0.45$ respectively. Self-reported hypertension was associated with a marginally significant increased risk (adjusted RR 1.47 (95\% CI 0.96-2.24)).

\section{Discussion}

In this prospective study, HDL-C levels were inversely associated with endometrial cancer risk, and glucose levels were positively associated with risk particularly among women who were postmenopausal or who had never used exogenous hormones. Total cholesterol, LDL-C, and triglyceride levels were not related to overall risk independent of BMI. The MetS was associated with an increased risk; this association was predominantly attributable to abdominal obesity, however, a clustering of the other MetS metabolic abnormalities was additionally associated with risk especially among overweight women.

Major strengths of this study are the relatively large sample size, and the prospective design that minimizes selection bias arising from inappropriate selection of control subjects. The prospective collection of blood samples at baseline, prior to cancer diagnosis, also avoids reverse causation bias that often occurs in studies of circulating lipid exposures (Law \& Thompson 1991). Laboratory variability was minimized using a central laboratory for lipid and hormone measurements, with blood samples from cases and their matched control subjects collected under identical conditions and always assayed together in the same batch.

A limitation of our study was the mixture of fasting and non-fasting blood samples in our study. Although 
Table 3 Relative risk estimates for endometrial cancer according to baseline lipid and glucose levels in all women

\begin{tabular}{|c|c|c|c|c|}
\hline Quartile cut-points (mmol/l) & $\begin{array}{c}\text { No. of } \\
\text { cases/controls }\end{array}$ & $\begin{array}{c}\text { Crude }^{a} \mathbf{R R} \\
\quad(95 \% \mathrm{Cl})\end{array}$ & $\begin{array}{l}\text { BMI-adjusted RR } \\
\qquad(95 \% \mathrm{Cl})\end{array}$ & $\begin{array}{c}\text { Full adjustment } \\
(95 \% \mathrm{Cl})\end{array}$ \\
\hline \multicolumn{5}{|l|}{ Total cholesterol } \\
\hline$\leq 4.36$ & $85 / 138$ & 1.00 & 1.00 & 1.00 \\
\hline $4.37-4.85$ & $65 / 131$ & $0.82(0.55-1.24)$ & $0.80(0.53-1.22)$ & $0.82(0.44-1.51)$ \\
\hline $4.86-5.40$ & $56 / 141$ & $0.65(0.42-0.99)$ & $0.66(0.43-1.02)$ & $0.76(0.36-1.61)$ \\
\hline$\geq 5.41$ & $78 / 136$ & $0.92(0.60-1.40)$ & $0.90(0.59-1.39)$ & $1.27(0.49-3.29)$ \\
\hline $\begin{array}{r}P_{\text {trend }} \\
\text { HDL-C }\end{array}$ & & 0.45 & 0.45 & 0.60 \\
\hline$\leq 1.13$ & $101 / 133$ & 1.00 & 1.00 & 1.00 \\
\hline $1.14-1.35$ & $74 / 143$ & $0.62(0.41-0.93)$ & $0.69(0.45-1.04)$ & $0.95(0.56-1.60)$ \\
\hline $1.36-1.58$ & $51 / 133$ & $0.44(0.28-0.68)$ & $0.50(0.32-0.78)$ & $0.88(0.46-1.68)$ \\
\hline$\geq 1.59$ & $58 / 137$ & $0.46(0.30-0.72)$ & $0.61(0.38-0.97)$ & $1.41(0.54-3.68)$ \\
\hline $\begin{array}{l}P_{\text {trend }} \\
\text { LDL-C }\end{array}$ & & 0.0003 & 0.02 & 0.72 \\
\hline$\leq 2.40$ & $72 / 137$ & 1.00 & 1.00 & 1.00 \\
\hline $2.40-2.88$ & $66 / 136$ & $0.95(0.63-1.43)$ & $0.93(0.61-1.41)$ & $1.22(0.67-2.24)$ \\
\hline 2.89-3.37 & $71 / 136$ & $1.02(0.68-1.54)$ & $1.04(0.68-1.57)$ & $1.61(0.74-3.51)$ \\
\hline$\geq 3.38$ & $75 / 137$ & $1.06(0.70-1.61)$ & $1.02(0.66-1.56)$ & $2.14(0.74-6.21)$ \\
\hline \multicolumn{5}{|l|}{ Triglycerides $^{c}$} \\
\hline Q1 & $64 / 130$ & 1.00 & 1.00 & 1.00 \\
\hline Q2 & $54 / 129$ & $0.88(0.56-1.39)$ & $0.86(0.54-1.35)$ & $1.03(0.60-1.77)$ \\
\hline Q3 & $60 / 128$ & $1.01(0.65-1.57)$ & $0.91(0.58-1.43)$ & $0.93(0.52-1.67)$ \\
\hline Q4 & $91 / 130$ & $1.51(0.98-2.32)$ & $1.28(0.82-1.99)$ & $2.08(0.96-4.54)$ \\
\hline$P_{\text {trend }}$ & & 0.04 & 0.22 & 0.20 \\
\hline \multicolumn{5}{|l|}{ Glucose $^{d}$} \\
\hline$\leq 3.86$ & $57 / 130$ & 1.00 & 1.00 & 1.00 \\
\hline $3.87-4.32$ & $51 / 132$ & $1.04(0.63-1.73)$ & $1.03(0.62-1.72)$ & $1.01(0.58-1.74)$ \\
\hline $4.33-4.69$ & $75 / 125$ & $1.75(1.04-2.96)$ & $1.63(0.95-2.78)$ & 1.59 (0.89-2.83) \\
\hline$\geq 4.70$ & $89 / 136$ & 1.95 (1.16-3.29) & $1.69(0.99-2.90)$ & $1.62(0.89-2.95)$ \\
\hline$P_{\text {trend }}$ & & 0.005 & 0.03 & 0.09 \\
\hline
\end{tabular}

${ }^{a}$ Adjusted for matching factors only: study center, baseline menopausal status, age at blood collection, time of day of blood collection, fasting status, and in premenopausal women, phase of menstrual cycle.

bIn addition to adjustment for matching factors, the models were mutually adjusted for the other factors in this table, as well as BMI, C-peptide, IGFBP-1, -2, adiponectin, SHBG, free testosterone, and estrone.

${ }^{\mathrm{c}}$ For triglycerides, different cut-points were used according to fasting status; cut-points for fasting subjects $(n=266)$ were $\leq 0.71$, $0.72-0.91,0.92-1.15, \geq 1.16$; cut-points for non-fasting subjects $(n=520)$ were $\leq 0.910 .92-1.25,1.26-1.66, \geq 1.67$. A total of 15 cases and 29 matched controls with unknown fasting status were excluded from triglyceride analyses.

dExcludes all 35 women recruited at the Oxford center.

total cholesterol and HDL-C levels are unaffected by acute fasting status, non-fasting measurements of triglycerides, glucose, and LDL-C may be less reliable because they can be influenced by recent food intake (Ahmed et al. 1976, Rifai et al. 1990, Wilder et al. 1995). Nevertheless, only triglyceride levels differed by fasting status in our study; thus, we used different quartile cut-points for fasting and non-fasting triglyceride levels. We also matched cases and controls according to fasting status and time of day of blood collection in order to minimize this variation. Although the risk estimates were generally slightly lower among non-fasting than fasting women, none of these differences were statistically significant.

Another limitation was the use of a single measurement from one baseline blood sample that does not fully reflect long-term circulating levels. Other studies have found little intra-individual variation in levels of total cholesterol, HDL-C, LDL-C, and glucose over a 1-year period (Demacker et al. 1982, Shumak \& Campbell 1993, Muti et al. 2002). However, triglycerides may be subject to considerable biologic variation even in fasting samples (Demacker et al. 1982, Shumak \& Campbell 1993). Another potential source of variation is from longterm storage. Average decreases in lipid and lipoprotein concentrations of about 1-3\% per year have been observed when stored at -70 to $-80{ }^{\circ} \mathrm{C}$ up to 7 years (Kronenberg et al. 1994, Shih et al. 2000). Glucose concentrations in plasma stored at $-20{ }^{\circ} \mathrm{C}$ may degrade up to $10 \%$ over 1 year (Clark et al. 1990), however, less degradation is expected in EPIC samples, which were stored at $-196^{\circ} \mathrm{C}$. 
Table 4 Relative risk estimates for the associations of endometrial cancer with plasma HDL-C and glucose levels stratified by baseline menopausal status

\begin{tabular}{|c|c|c|c|c|c|c|}
\hline \multirow[b]{2}{*}{$\begin{array}{l}\text { Tertile cut- } \\
\text { points }^{\mathrm{a}}(\mathrm{mmol} / \mathrm{l})\end{array}$} & \multicolumn{2}{|c|}{ Premenopausal $(n=159)$} & \multicolumn{2}{|c|}{$\begin{array}{l}\text { Perimenopausal/unknown } \\
\qquad(n=109)\end{array}$} & \multicolumn{2}{|c|}{ Postmenopausal $(n=562)$} \\
\hline & $\begin{array}{l}\text { No. of cases/ } \\
\text { controls }\end{array}$ & $\begin{array}{c}\text { BMI-adjusted } \\
\text { RRs }^{\mathbf{b}}(95 \% \mathrm{Cl})\end{array}$ & $\begin{array}{l}\text { No. of cases/ } \\
\text { controls }\end{array}$ & $\begin{array}{l}\text { BMI-adjusted } \\
\text { RRs }^{\mathbf{b}}(95 \% \mathrm{Cl})\end{array}$ & $\begin{array}{l}\text { No. of cases/ } \\
\text { controls }\end{array}$ & $\begin{array}{l}\text { BMl-adjusted } \\
\text { RRs }^{\mathbf{b}}(95 \% \mathrm{Cl})\end{array}$ \\
\hline \multicolumn{7}{|l|}{ HDL-C } \\
\hline$\leq 1.20$ & $19 / 31$ & 1.00 & $19 / 18$ & 1.00 & $92 / 135$ & 1.00 \\
\hline $1.21-1.47$ & $19 / 36$ & $0.88(0.37-2.06)$ & $8 / 27$ & $0.20(0.06-0.67)$ & $51 / 115$ & $0.66(0.41-1.04)$ \\
\hline$\geq 1.48$ & $16 / 38$ & $0.68(0.27-1.69)$ & $11 / 26$ & $0.30(0.09-1.02)$ & $49 / 120$ & $0.67(0.41-1.07)$ \\
\hline $\begin{array}{l}P_{\text {trend }} \\
\text { Glucose }^{\mathrm{c}}\end{array}$ & & 0.40 & & 0.08 & & 0.09 \\
\hline$\leq 4.04$ & $22 / 41$ & 1.00 & $11 / 20$ & 1.00 & $43 / 113$ & 1.00 \\
\hline $4.05-4.54$ & $19 / 29$ & $1.12(0.42-2.98)$ & $9 / 25$ & $0.61(0.18-2.15)$ & $45 / 118$ & $1.22(0.69-2.15)$ \\
\hline$\geq 4.55$ & $9 / 27$ & $0.47(0.15-1.52)$ & $17 / 24$ & $1.07(0.32-3.56)$ & $97 / 126$ & $2.61(1.46-4.66)$ \\
\hline$P_{\text {trend }}$ & & 0.26 & & 0.82 & & 0.0006 \\
\hline
\end{tabular}

aTertile cut-points $(\mathrm{mmol} / \mathrm{l})$ were based on the distribution of the variable among control subjects in the full study group.

${ }^{\mathrm{b}}$ The analysis was matched on study center, baseline menopausal status, age at blood collection, time of day of blood collection, fasting status, and in premenopausal women, phase of menstrual cycle. Additional adjustment was made for BMI.

${ }^{\mathrm{c} E x c l u d e s}$ all 35 women recruited at the Oxford center.

We observed an inverse association between HDL-C levels and endometrial cancer risk in our study. In a cross-sectional study of premenopausal women (Furberg et al. 2005), low serum HDL-C was associated with increased free estradiol levels but unchanged progesterone levels, thus reflecting increased exposure to unopposed estrogens that is a major etiologic determinant of endometrial cancer (Kaaks et al. 2002). Similarly in our study, HDL-C levels were negatively correlated with estrogens, measures of adiposity, and C-peptide and positively correlated with SHBG and adiponectin. Endogenous sex steroid hormones, particularly androgens, regulate HDL-C and other lipid levels through their action on hepatic triglyceride lipase activity and lipolysis (Haffner \& Valdez 1995). Although it has been proposed that low HDL-C could be a potential relevant marker for endometrial cancer risk (Furberg et al. 2005), the HDL-risk association was not independent of other obesity-related hormones in our study. Consistent with our findings, a previous prospective study with 448 cases (Hiatt \& Fireman 1986) also found no overall association between total cholesterol levels and risk. Another prospective study with 130 cases (Furberg \& Thune 2003) observed weak ageadjusted inverse associations between serum total cholesterol, HDL-C and risk, and no association with triglycerides.

High glucose levels could increase risk by acting as an energy source for the proliferation of tumor cells (Goldman et al. 2006), generating free radicals, or causing oxidative damage to DNA and DNA repair enzymes (Sun 1990, Dandona et al. 1996). Glucose transporter (GLUT) 1, 4, and 8 expression is upregulated in endometrial cancer cells, and may be linked to tumor progression and differentiation (Goldman et al. 2006, Shibata et al. 2007). Previous, smaller, prospective (Furberg \& Thune 2003), and case-control (Levran et al. 1984, Rutanen et al. 1993) studies have also observed increased risks associated with high glucose levels. In addition, type 2 diabetes, which is characterized by elevated glucose and insulin levels, is associated with increased endometrial cancer risk (Weiderpass et al. 2000, Anderson et al. 2001). Uterine GLUT expression and glucose transport are differentially regulated by estrogen and progesterone (Medina et al. 2004), and thus may be influenced by endogenous hormones and previous or current use of HRT or OCs. This effect might explain the stronger associations between glucose and endometrial cancer risk among never-users compared with previous users in our study. Future studies should address the potential modifying effect of OC or HRT on glucose pathways, according to the dose and potency of the estrogens and progestins in the formulations.

The presence of the MetS at baseline was associated with a 2.1-fold increased endometrial cancer risk using the NCEP definition and a 1.7-fold increased risk using the IDF definition. The difference in RRs between the definitions is likely to be due to the different obesity cut-points, as obesity is strongly associated with endometrial cancer (Kaaks et al. 2002). As data on pharmacologic treatments were not available, it is possible that we have slightly underestimated the 
Table 5 Relative risk estimates for endometrial cancer according to the diagnosis of metabolic syndrome and its component factors at baseline, in all women

\begin{tabular}{|c|c|c|c|}
\hline & Percent $^{\mathrm{a}}$ of cases/controls & Crude $^{\mathrm{b}} \mathbf{R R}(95 \% \mathrm{Cl})$ & Adjusted RR $(95 \% \mathrm{Cl})$ \\
\hline \multicolumn{4}{|l|}{ Metabolic syndrome (MetS) } \\
\hline NCEP definition & $36.4 / 22.8$ & $2.12(1.51-2.97)$ & $1.62(1.08-2.41)^{\mathrm{c}}$ \\
\hline IDF definition & $38.9 / 28.2$ & $1.68(1.23-2.31)$ & $1.20(0.82-1.75)^{\mathrm{c}}$ \\
\hline \multicolumn{4}{|c|}{ MetS individual component factors } \\
\hline $\begin{array}{l}\text { Abdominal obesity, NCEP cut- } \\
\text { point }(\geq 88 \mathrm{~cm})\end{array}$ & $45.7 / 29.7$ & $2.25(1.62-3.13)$ & $2.00(1.41-2.84)^{\mathrm{e}}$ \\
\hline $\begin{array}{l}\text { Abdominal obesity, IDF cut- } \\
\text { point }(\geq 80 \mathrm{~cm})\end{array}$ & $67.5 / 59.3$ & $1.48(1.09-2.02)$ & $1.26(0.91-1.75)^{\mathrm{e}}$ \\
\hline $\begin{array}{l}\text { Elevated triglycerides } \\
(\geq 1.7 \mathrm{mmol} / \mathrm{l})\end{array}$ & $26.8 / 20.0$ & $1.49(1.05-2.11)$ & $1.14(0.78-1.66)^{\mathrm{e}}$ \\
\hline Low HDL-C $(<1.29 \mathrm{mmol} / \mathrm{l})$ & $52.1 / 41.7$ & $1.64(1.21-2.23)$ & $1.34(0.96-1.87)^{\mathrm{e}}$ \\
\hline Raised blood pressure ${ }^{d}$ & $60.7 / 57.4$ & $1.18(0.86-1.63)$ & $0.95(0.67-1.34)^{\mathrm{e}}$ \\
\hline $\begin{array}{l}\text { Impaired glucose metabo- } \\
\text { lism }^{\text {d }}\end{array}$ & $10.4 / 7.1$ & $1.55(0.92-2.60)$ & $1.33(0.78-2.27)^{e}$ \\
\hline \multicolumn{4}{|c|}{ Number of MetS factors (NCEP definition) } \\
\hline Zero factors & $15.0 / 21.3$ & 1.00 (referent) & 1.00 (referent) $^{\mathrm{c}}$ \\
\hline One factor & $26.4 / 32.9$ & $1.22(0.78-1.93)$ & $1.12(0.70-1.78)$ \\
\hline Two factors & $22.1 / 23.0$ & $1.53(0.93-2.52)$ & $1.26(0.73-2.16)$ \\
\hline Three factors & $22.9 / 14.8$ & $2.57(1.52-4.32)$ & $1.89(1.03-3.47)$ \\
\hline Four or five factors ${ }^{f}$ & 13.6/8.0 & $2.95(1.60-5.45)$ & $1.98(0.95-4.14)$ \\
\hline$P_{\text {trend }}$ & & $<0.0001$ & 0.02 \\
\hline \multicolumn{4}{|c|}{ Number of non-waist MetS component factors, stratified by the median waist circumference } \\
\hline \multicolumn{4}{|c|}{ Waist circumference below the median $(<83.0 \mathrm{~cm}, n=403)$} \\
\hline Zero factors & $30.3 / 33.5$ & 1.00 & $1.00^{\mathrm{g}}$ \\
\hline One factor & $45.4 / 40.5$ & $0.99(0.50-1.96)$ & $0.98(0.49-1.96)$ \\
\hline Two factors & $15.1 / 20.4$ & $0.56(0.24-1.32)$ & $0.55(0.23-1.34)$ \\
\hline Three or four factors ${ }^{f}$ & $9.2 / 5.6$ & $1.80(0.47-6.84)$ & $1.76(0.45-6.86)$ \\
\hline & \multicolumn{2}{|c|}{ Waist circumference above the median ( $\geq 83.0 \mathrm{~cm}, n=412$ ) } & 0.69 \\
\hline Zero factors & $7.5 / 16.3$ & 1.00 & $1.00^{\mathrm{g}}$ \\
\hline One factor & $28.6 / 35.1$ & $1.73(0.62-4.80)$ & $1.53(0.54-4.34)$ \\
\hline Two factors & $40.4 / 24.3$ & $4.75(1.65-13.67)$ & $4.02(1.37-11.83)$ \\
\hline Three or four factors ${ }^{f}$ & $23.6 / 24.3$ & $2.54(0.81-7.94)$ & $2.06(0.63-6.75)$ \\
\hline$P_{\text {trend }}$ & & 0.02 & 0.06 \\
\hline$P_{\text {interaction }}$ & & 0.009 & 0.01 \\
\hline
\end{tabular}

apercent of cases (total $=280$ ) and controls (total $=535)$ that were classified as meeting the respective criteria.

${ }^{\mathrm{b}}$ The analysis was matched on study center, baseline menopausal status, age at blood collection, time of day of blood collection, fasting status, and in premenopausal women, phase of menstrual cycle.

${ }^{\mathrm{c}}$ Abdominal obesity, by definition, is a component of the MetS. However, these models were additionally adjusted for waist circumference as a continuous variable to estimate the extent to which the increased risk could be explained by obesity.

${ }^{\mathrm{d}}$ The reference category for each factor included women not meeting the respective criteria. Raised blood pressure was defined as systolic blood pressure $\geq 130 \mathrm{mmHg}$ or diastolic blood pressure $\geq 85 \mathrm{mmHg}$ or self-reported hypertension. Impaired glucose metabolism was defined as glucose $\geq 5.6 \mathrm{mmol} / \mathrm{l}$ or self-reported diabetes.

e Individual component factors were mutually adjusted for the other MetS metabolic factors (categories) and waist circumference (continuous).

${ }^{\mathrm{t}}$ The highest two categories were combined due to few numbers in the highest category.

${ }^{g}$ Additionally adjusted for waist circumference as a continuous variable.

prevalence of MetS in our study population, and the RRs may be slightly over- or underestimated. Another prospective study (Furberg \& Thune 2003) reported a 1.9-fold increased risk (95\% CI 0.84-4.34) associated with a cluster of similar metabolic abnormalities (excluding obesity), but only six cases were included in their analysis. In our study, the MetS-risk association may be largely explained by the presence of abdominal obesity. In postmenopausal women, the conversion of androgens to estrogens occurs in adipose tissue, thus the level of adiposity directly influences the amount of circulating estrogens (Key \& Pike 1988, Kaaks et al. 2002). In premenopausal women, obesity can cause anovulation and decreased progesterone and estrogen levels (Kaaks et al. 2002).

In addition, obesity is a major determinant of insulin resistance (Bergman \& Mittelman 1998), and they are both key characteristics of the MetS (Grundy et al. 
2005). Insulin resistance (Cust et al. 2007b) and hyperinsulinemia (Lukanova et al. 2004, Cust et al. 2007a) may also be associated with increased endometrial cancer risk independently of obesity. Insulin may act directly on endometrial tissue as a mitogenic and anti-apoptotic growth factor (Nagamani \& Stuart 1998). Insulin can also increase IGF-I bioactivity (Kaaks \& Lukanova 2001, Kaaks et al. 2002), and increase the bioavailability of free estrogens and androgens through downregulation of SHBG and upregulation of ovarian sex steroid production (Kaaks \& Lukanova 2001, Kaaks et al. 2002).

Overall, there was a statistically significant doseresponse trend between the number of MetS metabolic abnormalities and endometrial cancer risk. Although interrelated, these factors may reflect different aspects of an underlying metabolic disturbance, and the presence of more factors may express less misclassification. This relation could be confounded by obesity because the presence of other metabolic abnormalities may be related to higher levels of adiposity; however, the association remained statistically significant after finer adjustment for waist circumference.

Further analysis showed that the dose-response trend between the number of non-waist MetS factors and risk was more evident among women above the median waist circumference. Several other studies have also reported potential modifying effects of obesity on associations between metabolic disturbances and risk. In some studies, hypertension (Weiderpass et al. 2000, Furberg \& Thune 2003), diabetes (Shoff \& Newcomb 1998, Salazar-Martinez et al. 2000, Anderson et al. 2001), glucose levels (Furberg \& Thune 2003), and the consumption of high-glycemic load foods (Larsson et al. 2007) have been found to be positively associated with endometrial cancer risk only among overweight or obese women. Low adiponectin levels (a marker of insulin resistance) are also associated with increased risk particularly among obese women (Cust et al. 2007b), and low serum HDL-C levels and a high LDL-C/HDL-C ratio have been found to predict increased bioavailable estradiol levels more strongly among overweight than normal-weight women (Furberg et al. 2005). Thus, overweight women may experience a heightened physiologic response to the presence of other metabolic factors compared with leaner women.

In conclusion, these findings support the hypothesis that obesity and other metabolic disturbances may act synergistically to facilitate malignant transformation of endometrial cells (Furberg \& Thune 2003). Further prospective epidemiologic and experimental studies are needed to clarify the underlying biologic mechanisms for these associations. Strategies to reduce the incidence of endometrial cancer should target the prevention and treatment of obesity and related metabolic disorders.

\section{Acknowledgements}

We thank Joëlle Goudable for overseeing the laboratory analyses, Laure Dossus and Carine Biessy for database management and statistical advice, Michael Skilton for his comments on the draft manuscript, and all participants and staff involved in the EPIC study.

Anne Cust is supported by a PhD scholarship from the University of Sydney and a Research Scholar Award from the Cancer Institute NSW, Australia. Christine Friedenreich is supported by a Canadian Institutes of Health Research New Investigator Award and an Alberta Heritage Foundation for Medical Research Health Scholar Award. The EPIC study has received financial support from the 'Europe Against Cancer Program' of the European Commission (SANCO); Danish Cancer Society; German Cancer Aid; Ligue Nationale contre le Cancer, 3M Company, INSERM; German Cancer Research Center; German Federal Ministry of Education and Research; Dutch Ministry of Public Health, Welfare and Sports; National Cancer Registry and the Regional Cancer Registries Amsterdam, East and Maastricht of The Netherlands; Norwegian Cancer Society; Norwegian Research Council; Health Research Fund (FIS) of the Spanish Ministry of Health; the ISCIII Network RCESP (C03/09) and RETICC C03/10, Spanish Regional Governments of Andalusia, Asturias, Basque Country, Murcia and Navarra, and the Catalan Institute of Oncology; Greek Ministry of Health; Greek Ministry of Education; Italian Association for Research on Cancer; Swedish Cancer Society; Swedish Scientific Council; Regional Government of Skane, Sweden; Cancer Research UK; Medical Research Council, UK; Stroke Association, UK; British Heart Foundation; Department of Health, UK; Food Standards Agency, UK; Wellcome Trust, UK and the Fondation de France (2005011204\&207). The authors declare that there is no conflict of interest that would prejudice the impartiality of this scientific work.

\section{References}

Ahmed M, Gannon MC \& Nuttall FQ 1976 Postprandial plasma glucose, insulin, glucagon and triglyceride responses to a standard diet in normal subjects. Diabetologia 12 61-67.

Alberti KG, Zimmet P \& Shaw J 2006 Metabolic syndrome a new world-wide definition. A Consensus Statement from the International Diabetes Federation. Diabetic Medicine 23 469-480. 
Anderson KE, Anderson E, Mink PJ, Hong CP, Kushi LH, Sellers TA, Lazovich D \& Folsom AR 2001 Diabetes and endometrial cancer in the Iowa women's health study. Cancer Epidemiology, Biomarkers and Prevention 10 611-616.

Bergman RN \& Mittelman SD 1998 Central role of the adipocyte in insulin resistance. Journal of Basic and Clinical Physiology and Pharmacology 9 205-221.

Boyanton BL Jr \& Blick KE 2002 Stability studies of twentyfour analytes in human plasma and serum. Clinical Chemistry 48 2242-2247.

Bradley DD, Wingerd J, Petitti DB, Krauss RM \& Ramcharan S 1978 Serum high-density-lipoprotein cholesterol in women using oral contraceptives, estrogens and progestins. New England Journal of Medicine 299 17-20.

Calle EE \& Kaaks R 2004 Overweight, obesity and cancer: epidemiological evidence and proposed mechanisms. Nature Reviews. Cancer 4 579-591.

Clark ML, Humphreys SM \& Frayn KN 1990 Stability of plasma glucose during storage. Annals of Clinical Biochemistry 27 373-377.

Cust AE, Allen NE, Rinaldi S, Dossus L, Friedenreich C, Olsen A, Tjonneland A, Overvad K, Clavel-Chapelon F, Boutron-Ruault MC et al. 2007a Serum levels of C-peptide, IGFBP-1 and IGFBP-2 and endometrial cancer risk; results from the European prospective investigation into cancer and nutrition. International Journal of Cancer 120 2656-2664.

Cust AE, Kaaks R, Friedenreich C, Bonnet F, Laville M, Lukanova A, Rinaldi S, Dossus L, Slimani N, Lundin E et al. 2007b Plasma adiponectin levels and endometrial cancer risk in pre- and postmenopausal women. Journal of Clinical Endocrinology and Metabolism 92 255-263.

Dandona P, Thusu K, Cook S, Snyder B, Makowski J, Armstrong D \& Nicotera T 1996 Oxidative damage to DNA in diabetes mellitus. Lancet 347 444-445.

Demacker PN, Schade RW, Jansen RT \& Van't Laar A 1982 Intra-individual variation of serum cholesterol, triglycerides and high density lipoprotein cholesterol in normal humans. Atherosclerosis 45 259-266.

Elgee NJ 1970 Medical aspects of oral contraceptives. Annals of Internal Medicine 72 409-418.

Friedewald WT, Levy RI \& Fredrickson DS 1972 Estimation of the concentration of low-density lipoprotein cholesterol in plasma, without use of the preparative ultracentrifuge. Clinical Chemistry 18 499-502.

Furberg AS \& Thune I 2003 Metabolic abnormalities (hypertension, hyperglycemia and overweight), lifestyle (high energy intake and physical inactivity) and endometrial cancer risk in a Norwegian cohort. International Journal of Cancer 104 669-676.

Furberg AS, Jasienska G, Bjurstam N, Torjesen PA, Emaus A, Lipson SF, Ellison PT \& Thune I 2005 Metabolic and hormonal profiles: HDL cholesterol as a plausible biomarker of breast cancer risk. The Norwegian EBBA Study. Cancer Epidemiology, Biomarkers and Prevention 14 33-40.
Goldman NA, Katz EB, Glenn AS, Weldon RH, Jones JG, Lynch U, Fezzari MJ, Runowicz CD, Goldberg GL \& Charron MJ 2006 GLUT1 and GLUT8 in endometrium and endometrial adenocarcinoma. Modern Pathology 19 1429-1436.

Grundy SM, Cleeman JI, Daniels SR, Donato KA, Eckel RH, Franklin BA, Gordon DJ, Krauss RM, Savage PJ, Smith SC Jr et al. 2005 Diagnosis and management of the metabolic syndrome: an American Heart Association/National Heart, Lung, and Blood Institute Scientific Statement. Circulation 112 2735-2752.

Haffner SM \& Valdez RA 1995 Endogenous sex hormones: impact on lipids, lipoproteins, and insulin. American Journal of Medicine $\mathbf{9 8}$ 40S-47S.

Haftenberger M, Schuit AJ, Tormo MJ, Boeing H, Wareham N, Bueno-de-Mesquita HB, Kumle M, Hjartaker A, Chirlaque MD, Ardanaz E et al. $2002 a$ Physical activity of subjects aged 50-64 years involved in the European Prospective Investigation into Cancer and Nutrition (EPIC). Public Health Nutrition 5 1163-1176.

Haftenberger M, Lahmann PH, Panico S, Gonzalez CA, Seidell JC, Boeing H, Giurdanella MC, Krogh V, Buenode-Mesquita HB, Peeters PH et al. 2002b Overweight, obesity and fat distribution in 50- to 64-year-old participants in the European Prospective Investigation into Cancer and Nutrition (EPIC). Public Health Nutrition 5 1147-1162.

Hankinson SE, London SJ, Chute CG, Barbieri RL, Jones L, Kaplan LA, Sacks FM \& Stampfer MJ 1989 Effect of transport conditions on the stability of biochemical markers in blood. Clinical Chemistry 35 2313-2316.

Hiatt RA \& Fireman BH 1986 Serum cholesterol and the incidence of cancer in a large cohort. Journal of Chronic Diseases 39 861-870.

Kaaks R \& Lukanova A 2001 Energy balance and cancer: the role of insulin and insulin-like growth factor-I. Proceedings of the Nutrition Society 60 91-106.

Kaaks R, Lukanova A \& Kurzer MS 2002 Obesity, endogenous hormones, and endometrial cancer risk: a synthetic review. Cancer Epidemiology, Biomarkers and Prevention 11 1531-1543.

Kaaks R, Berrino F, Key T, Rinaldi S, Dossus L, Biessy C, Secreto G, Amiano P, Bingham S, Boeing H et al. 2005 Serum sex steroids in premenopausal women and breast cancer risk within the European Prospective Investigation into Cancer and Nutrition (EPIC). Journal of National Cancer Institute 97 755-765.

Key TJ \& Pike MC 1988 The dose-effect relationship between 'unopposed' oestrogens and endometrial mitotic rate: its central role in explaining and predicting endometrial cancer risk. British Journal of Cancer 57 205-212.

Kronenberg F, Lobentanz EM, Konig P, Utermann G \& Dieplinger H 1994 Effect of sample storage on the measurement of lipoprotein[a], apolipoproteins B and AIV, total and high density lipoprotein cholesterol and triglycerides. Journal of Lipid Research 35 1318-1328. 
Larsson SC, Friberg E \& Wolk A 2007 Carbohydrate intake, glycemic index and glycemic load in relation to risk of endometrial cancer: A prospective study of Swedish women. International Journal of Cancer 120 1103-1107.

Law MR \& Thompson SG 1991 Low serum cholesterol and the risk of cancer: an analysis of the published prospective studies. Cancer Causes and Control 2 253-261.

Levran D, Modan M, Menczer J \& Dulitzy M 1984 Increased rate of glucose intolerance in endometrial cancer - a community-based study. Gynecologic and Obstetric Investigation 18 190-193.

Lukanova A, Zeleniuch-Jacquotte A, Lundin E, Micheli A, Arslan AA, Rinaldi S, Muti P, Lenner P, Koenig KL, Biessy C et al. 2004 Prediagnostic levels of C-peptide, IGF-I, IGFBP -1, -2 and -3 and risk of endometrial cancer. International Journal of Cancer 108 262-268.

Medina RA, Meneses AM, Vera JC, Guzman C, Nualart F, Rodriguez F, de los Angeles Garcia M, Kato S, Espinoza N, Monso C et al. 2004 Differential regulation of glucose transporter expression by estrogen and progesterone in Ishikawa endometrial cancer cells. Journal of Endocrinology 182 467-478.

Muti P, Quattrin T, Grant BJ, Krogh V, Micheli A, Schunemann HJ, Ram M, Freudenheim JL, Sieri S, Trevisan M et al. 2002 Fasting glucose is a risk factor for breast cancer: a prospective study. Cancer Epidemiology, Biomarkers and Prevention 11 1361-1368.

Nagamani M \& Stuart CA 1998 Specific binding and growthpromoting activity of insulin in endometrial cancer cells in culture. American Journal of Obstetrics and Gynaecology 179 6-12.

Riboli E \& Kaaks R 1997 The EPIC Project: rationale and study design. Investigation into Cancer and Nutrition. International Journal of Epidemiology 26 S6-S14.

Riboli E, Hunt KJ, Slimani N, Ferrari P, Norat T, Fahey M, Charrondiere UR, Hemon B, Casagrande C, Vignat J et al. 2002 European prospective investigation into cancer and nutrition (EPIC): study populations and data collection.

Public Health Nutrition 5 1113-1124.

Richardson DB 2004 An incidence density sampling program for nested case-control analyses. Occupational and Environmental Medicine 61 e59.

Rifai N, Merrill JR \& Holly RG 1990 Postprandial effect of a high fat meal on plasma lipid, lipoprotein cholesterol and apolipoprotein measurements. Annals of Clinical Biochemistry 27 489-493.

Rutanen EM, Stenman S, Blum W, Karkkainen T, Lehtovirta P \& Stenman UH 1993 Relationship between carbohydrate metabolism and serum insulin-like growth factor system in postmenopausal women: comparison of endometrial cancer patients with healthy controls. Journal of Clinical Endocrinology and Metabolism 77 199-204.
Salazar-Martinez E, Lazcano-Ponce EC, Lira-Lira GG, Escudero-De los Rios P, Salmeron-Castro J, Larrea F \& Hernandez-Avila M 2000 Case-control study of diabetes, obesity, physical activity and risk of endometrial cancer among Mexican women. Cancer Causes and Control 11 707-711.

Sherman ME 2000 Theories of endometrial carcinogenesis: a multidisciplinary approach. Modern Pathology 13 295-308.

Shibata K, Kajiyama H, Ino K, Nawa A, Nomura S, Mizutani S \& Kikkawa F 2007 P-LAP/IRAP-induced cell proliferation and glucose uptake in endometrial carcinoma cells via insulin receptor signaling. $B M C$ Cancer 715 .

Shih WJ, Bachorik PS, Haga JA, Myers GL \& Stein EA 2000 Estimating the long-term effects of storage at $-70{ }^{\circ} \mathrm{C}$ on cholesterol, triglyceride, and HDL-cholesterol measurements in stored sera. Clinical Chemistry 46 351-364.

Shoff SM \& Newcomb PA 1998 Diabetes, body size, and risk of endometrial cancer. American Journal of Epidemiology 148 234-240.

Shumak SL \& Campbell NR 1993 Intraindividual variation in lipid and lipoprotein levels. Canadian Medical Association Journal 149 843-844.

Sun Y 1990 Free radicals, antioxidant enzymes, and carcinogenesis. Free Radical Biology \& Medicine $\mathbf{8}$ 583-599.

Swanson CA, Potischman N, Barrett RJ, Berman ML, Mortel R, Twiggs LB, Wilbanks GD, Hoover RN \& Brinton LA 1994 Endometrial cancer risk in relation to serum lipids and lipoprotein levels. Cancer Epidemiology, Biomarkers and Prevention 3 575-581.

Wallace RB, Hoover J, Barrett-Connor E, Rifkind BM, Hunninghake DB, Mackenthun A \& Heiss G 1979 Altered plasma lipid and lipoprotein levels associated with oral contraceptive and oestrogen use. Report from the Medications Working Group of the Lipid Research Clinics Program. Lancet 2 112-115.

Weiderpass E, Persson I, Adami HO, Magnusson C, Lindgren A \& Baron JA 2000 Body size in different periods of life, diabetes mellitus, hypertension, and risk of postmenopausal endometrial cancer (Sweden). Cancer Causes and Control 11 185-192.

Wilder LB, Bachorik PS, Finney CA, Moy TF \& Becker DM 1995 The effect of fasting status on the determination of low-density and high-density lipoprotein cholesterol. American Journal of Medicine 99 374-377.

World Health Organization 2003 Pathology and genetics. Tumours of the breast and female genital organs. In World Health Organization Classification of Tumours, Eds FA Tavassoli \& D Devilee. Lyon: IARC Press. 